\title{
Needs-based innovation: the biodesign process
}

\section{Paul Yock}

Correspondence to

Dr Paul Yock, Stanford University, Stanford, California, USA; yock@stanford.edu

Accepted 4 November 2014
We usually think about innovation in the life sciences as being discovery-driven. Across university research laboratories and throughout the biotech and pharma industries, scientific breakthroughs have been the launching point for major product developments in the familiar bench-to-bedside trajectory.

Over the past decade, however, a focus on needs-based innovation has emerged as an alternate strategy for medical product development, particularly in the domain of biomedical technology (medical devices and diagnostics). Influenced by the spread of design thinking across campuses and corporations alike, innovators are beginning to focus on developing a deep understanding of clinical needs as the starting point of the invention process. ${ }^{1}$ The mantra for this biodesign process is that "a wellcharacterised need is the DNA of a great invention." 2

Admittedly, the biodesign process has some substantial complexities compared to the design of a consumer product. Most importantly, there is no simple customer profile to serve as the archetype for need identification. The stakeholder landscape in healthcare is exceedingly complicated, with multiple influencers and decision-makers affecting whether or not a technology will, in fact, be translated into clinical care. To characterise a need fully, innovators must understand not only the interplay between patients, providers and health systems, but also regulatory requirements, the existing framework for reimbursement and business dynamics in the marketplace. ${ }^{3}$

Although creating this multidimensional need profile can be a formidable job, in fact this method is highly efficient in that innovators discover the 'killer risks' much earlier than they would using a typical discovery-driven approach. The beauty of the biodesign process is that it allows innovators to pick the most promising needs to pursue before investing years and many millions of dollars in developing and testing a particular solution. This is a kind of 'frugal innovation' in its own right, where savings accrue simply from following the process.

A needs-based process also provides the opportunity to insert value as an up-front boundary condition for inventing a new technology. In fact, by starting with a value criterion in the specification of the need, innovators are much more likely to develop a solution that incorporates the most cost-effective combination of technologies, practices and systems to meet that need. This is a powerful way to break the cycle of cost escalation that has been associated with the introduction of new biomedical technologies.

Breakthrough scientific discoveries from universities and the industry will continue to provide important technology advances for patient care. But the emergence of the biodesign process, with its focus on needs-based invention is bringing both a new approach and a new mix of innovators into the life science ecosystem. Given the global crisis of healthcare affordability, it is particularly a good time to open the pipeline of innovations that are based on the real needs in health systems around the world.

\section{Competing interests None.}

Provenance and peer review Not commissioned; internally peer reviewed.

\section{REFERENCES}

1 Yock PG, Brinton TJ, Zenios SA. Teaching biomedical innovation as a discipline. Sci Transl Med 2011;3:92cm18.

2 Brinton TJ, Kurihara CQ, Camarillo DB, et al. Outcomes from a postgraduate biomedical technology innovation training program: the first 12 years of Stanford biodesign. Ann Biomed Eng 2013;41:1803-10.

3 Yock P, Zenios S, Makower J, et al. Biodesign: the process of innovating medical technologies. 2nd edn. Cambridge University Press, 2015. 